Marquette University

e-Publications@Marquette

School of Dentistry Faculty Research and

Publications

Dentistry, School of

$1-2017$

\title{
Cranio-Maxillofacial Reconstruction with Microvascular Radialis Flaps-Parameters and Correlations of Postoperative Pain
}

\section{Management}

\author{
Gregor F. Raschke \\ Friedrich Schiller University of Jena \\ Winfried Meissner \\ Friedrich Schiller University of Jena \\ Andre Peisker \\ Friedrich Schiller University of Jena \\ Gabriel Djedovic \\ Goethe University \\ Ulrich M. Rieger \\ Goethe University
}

See next page for additional authors

Follow this and additional works at: https://epublications.marquette.edu/dentistry_fac

Part of the Dentistry Commons

\section{Recommended Citation}

Raschke, Gregor F.; Meissner, Winfried; Peisker, Andre; Djedovic, Gabriel; Rieger, Ulrich M.; Guentsch, Arndt; Porwit, Daria; Gomez-Dammeier, Marta; and Schultze-Mosgau, Stefan, "Cranio-Maxillofacial Reconstruction with Microvascular Radialis Flaps-Parameters and Correlations of Postoperative Pain Management" (2017). School of Dentistry Faculty Research and Publications. 208.

https://epublications.marquette.edu/dentistry_fac/208 


\section{Authors}

Gregor F. Raschke, Winfried Meissner, Andre Peisker, Gabriel Djedovic, Ulrich M. Rieger, Arndt Guentsch, Daria Porwit, Marta Gomez-Dammeier, and Stefan Schultze-Mosgau 
Marquette University

e-Publications@Marquette

\title{
Dentistry Faculty Research and Publications/School of Dentistry
}

This paper is NOT THE PUBLISHED VERSION.

Access the published version at the link in the citation below.

Clinical Oral Investigations, Vol. 21, (2017): 429-436. DOI. This article is (C) Elsevier and permission has been granted for this version to appear in e-Publications@Marquette. Elsevier does not grant permission for this article to be further copied/distributed or hosted elsewhere without the express permission from Elsevier.

\section{Cranio-Maxillofacial Reconstruction with Microvascular Radialis Flaps-Parameters and Correlations of Postoperative Pain Management}

\author{
Gregor F. Raschke
}

Department of Cranio-Maxillofacial \& Plastic Surgery, Friedrich Schiller University Jena, Jena, Germany Winfried Meissner

Department of Anesthesiology and Intensive Care Medicine, Friedrich Schiller University Jena, Jena, Germany

Andre Peisker

Department of Cranio-Maxillofacial \& Plastic Surgery, Friedrich Schiller University Jena, Jena, Germany Gabriel Djedovic

Department of Plastic \& Aesthetic, Reconstructive and Hand Surgery, St. Markus Hospital, Johann Wolfgang von Goethe University, Frankfurt/Main, Germany

Ulrich Rieger 
Department of Plastic \& Aesthetic, Reconstructive and Hand Surgery, St. Markus Hospital, Johann Wolfgang von Goethe University, Frankfurt/Main, Germany

\section{Arndt Guentsch}

Marquette University School of Dentistry, Milwaukee, WI, USA

\section{Daria Porwit}

Department of Cranio-Maxillofacial \& Plastic Surgery, Friedrich Schiller University Jena, Jena, Germany

\section{Marta Gomez Dammeier}

Department of Cranio-Maxillofacial \& Plastic Surgery, Friedrich Schiller University Jena, Jena, Germany

\section{Stefan Schultze-Mosgau}

Department of Cranio-Maxillofacial \& Plastic Surgery, Friedrich Schiller University Jena, Jena, Germany

\section{Abstract \\ Objectives}

Postoperative pain management is of highest interest for patients undergoing maxillofacial surgery including microvascular reconstructive surgery. Currently, there is a lack of information regarding process and outcome of postoperative pain management after microvascular reconstruction.

\section{Materials and methods}

In a prospective clinical study, 31 adults were evaluated on the first postoperative day following microvascular reconstruction with a radial forearm flap using the standardized questionnaire of the Germany-wide project Quality Improvement in Postoperative Pain Management (QUIPS). It enables a standardized assessment of patients' characteristics, pain parameters, outcome and pain therapy process parameters.

\section{Results}

Pain management consisted predominately of premedication with midazolam, sufentanil and metamizol intraoperatively, piritramid in the intensive care unit and metamizol, tramadol and fentanyl patches on ward. Nineteen patients (61.3\%) showed inadequate pain management with pain levels $\geq 4$. Among other significant relations, patients exhibiting an age below the median presented significant higher levels of pain under strain $(p=.041)$ and maximum pain $(p=.006)$ as well as rate of breathing $(p=.009)$ and mood $(p=.006)$ disturbance. Performance of pain counselling showed specific impact on pain under strain $(p=.008)$, maximum pain $(p=.004)$ and satisfaction with pain intensity $(p=.001)$. Whether microvascular reconstruction was performed with primary or secondary intention or performance of a neck dissection did not show significant influence.

\section{Conclusions}

QUIPS helped us to adequately evaluate the procedure-specific quality of postoperative management following microvascular reconstruction with a radial forearm flap. It helped us to identify a surprisingly high amount of inadequate pain management. Postoperative pain levels seem to be primarily influenced by the performed reconstruction. 


\section{Clinical relevance}

Establishment of a continuous and procedure-specific evaluation of postoperative pain levels should help to avoid inadequate pain management, which is widely prevalent according to the literature and our study. Preoperative pain counselling is essential and should be procedure specific to be its best.

\section{Introduction}

Acute postoperative pain management is of biggest importance to all surgeons. Adequate postoperative pain management is not only an ethical obligation, it also helps to decrease suffering and decreases thereby postoperative morbidity, the rate of complications, hospital stay and costs [13].

Despite these facts, undersupply with adequate postoperative pain medication is a worldwide phenomenon [4-6]. Investigations from various countries confirm that the quality of acute pain management is insufficient [5, 7-10].

It was tried to improve this situation by establishing several clinical guidelines with quality indicators over the last decade. Processes and structures of pain management were optimized. However, outcomes such as pain intensity levels and incidence have not been improved [11, 12].

The analgetic effectivity of analgetics efficacy varies widely between different surgical procedures [2]. Thus, it should be considered to perform and evaluate acute postoperative pain management in a procedure-specific manner.

Regarding such a procedure-specific evaluation, an evaluation of microvascular reconstructive procedures is from special interest to cranio-maxillofacial surgeons. These reconstructions are among the most complex and complication-associated procedures in cranio-maxillofacial surgery. To date, there is a lack of knowledge in the literature regarding the procedure-specific quality of postoperative pain management after microvascular reconstruction.

In the presented prospective clinical study, we evaluated the quality of postoperative pain management in a series of patients undergoing microvascular transfer with a radialis flap. A standardized assessment of patients' characteristics, pain parameters, outcome and process parameters was conducted by using the standardized questionnaire of the Quality Improvement in Postoperative Pain Management (QUIPS) project. It enables a standardized data acquisition and an analysis of process and result parameters to investigate postoperative pain and its influencing parameters on the first postoperative day [13].

\section{Patients and method}

The presented prospective study was performed at the Department of Cranio-Maxillofacial Surgery/Plastic Surgery of the University Hospital Jena. Institutional review board approval was obtained prior to start of the study by the local ethics committee of the Medical Faculty of the University Hospital Jena. All patients able to answer the questions of the standardized questionnaire were included after signing informed consent. 
Patients who exhibited either a carcinoma of the oral soft tissues or an oral soft tissue defect related to other reasons were included. In case of first-time tumour surgery, the procedure started with an adequate neck dissection. Afterwards, radical resection of the tumour was performed. The radialis flap was harvested in a standardized manner as described earlier [14]. Donor site was closed with fullthickness skin graft from the upper arm of the same side. Simultaneously, microvascular anastomosis of the artery and at least one vein was performed. After completion and function of the microvascular anastomosis, wound closure was performed. All patients received a tracheotomy to secure the airway. In two cases, a relapsed carcinoma was locally radical resected. There was no additional lymph node surgery necessary. In case of a secondary reconstruction, we first looked for adequate vessels and when given, the recipient site was prepared for microvascular transfer.

After completion of surgery, patients were transferred to our intensive care unit, where weaning of sedation started. At the morning of the first postoperative day, all patients were transferred on ward.

A study nurse not being involved in the routine care of the patient performed the assessment of postoperative pain at the first postoperative day not exceeding $24 \mathrm{~h}$ after surgery.

After signalizing consent and a standardized instruction, the patient himself completed the first part of the QUIPS questionnaire covering outcome parameters of postoperative pain management:

- Pain under strain, maximum and minimum pain intensities during the last $24 \mathrm{~h}$ since surgery (numeric rating scale (NRS) $0-10,0=$ no pain, 10 highest imaginable pain level)

- Pain-related interference with physical activity (movement), coughing and deep breathing, sleep and mood over the last $24 \mathrm{~h}$ since surgery (NRS 0-10)

- Nausea or vomiting since surgery

- Wish to have received or receive additional doses of pain medication

- $\quad$ Patient satisfaction with postoperative analgesia outcome using a 16 box NRS $(0-15,0=$ very unsatisfied, 15 = very satisfied)

The second part of the questionnaire is covering the relevant patients' characteristics including, for example, age, gender, ASA status and duration of surgery. Furthermore, it serves to record the relevant process parameters of postoperative pain management. It was completed by the study nurse.

Statistical analysis

Data are presented as mean and standard deviation if not indicated otherwise. Outcome and process parameters are given descriptively (Tables 1 and 2). The continuous variables, age and duration of surgery, were transformed into dichotomous variables using the median values as separator. Nonparametric Man-Whitney $U$ test was applied to compare continuous variables between resulting independent subgroup pairs, and Kruskal-Wallis test was performed to compare results between multiple subgroups. Pearson's chi-square test was applied to compare categorized data of independent subgroups (see Tables 3 and 4). In cases were requirements for Pearson's chi-square test were not met, Fisher's exact test was applied. In cases were multiple groups were compared, nominal $p$ values of two-tailed tests are reported. A $p$ value of $<0.05$ was taken significant. 
Table 1 QUIPS outcome parameters after microvascular reconstruction with a radialis flap $(n=31$ patients)

\begin{tabular}{|c|c|}
\hline Pain on ambulation & $4.06 \pm 2.29$ \\
\hline Maximum pain intensity & $5.39 \pm 2.50$ \\
\hline Minimum pain intensity & $2.06 \pm 1.84$ \\
\hline Satisfaction with pain intensity & $11.58 \pm 2.49$ \\
\hline \multicolumn{2}{|c|}{ Preoperative pain management counselling } \\
\hline Yes, only general & 24 \\
\hline Yes, also specific & 3 \\
\hline No & 4 \\
\hline \multicolumn{2}{|l|}{ Chronic pain before surgery } \\
\hline Yes & 6 \\
\hline No & 25 \\
\hline \multicolumn{2}{|c|}{ Mobility impairment because of pain } \\
\hline Yes & 17 \\
\hline No & 14 \\
\hline \multicolumn{2}{|c|}{ Breathing impairment because of pain } \\
\hline Yes & 12 \\
\hline No & 19 \\
\hline \multicolumn{2}{|c|}{ Sleeping impairment because of pain } \\
\hline Yes & 15 \\
\hline No & 16 \\
\hline \multicolumn{2}{|l|}{ Mood impairment because of pain } \\
\hline Yes & 14 \\
\hline No & 17 \\
\hline \multicolumn{2}{|l|}{ Desire for pain medication } \\
\hline Yes & 11 \\
\hline No & 20 \\
\hline \multicolumn{2}{|l|}{ Drowsiness since surgery } \\
\hline Yes & 25 \\
\hline No & 6 \\
\hline \multicolumn{2}{|l|}{ Nausea since surgery } \\
\hline Yes & 14 \\
\hline No & 17 \\
\hline \multicolumn{2}{|l|}{ Vomiting since surgery } \\
\hline Yes & 6 \\
\hline No & 25 \\
\hline
\end{tabular}

Table 2 QUIPS outcome parameters after microvascular reconstruction with a radialis flap $(n=31$ patients)

\begin{tabular}{|l|l|}
\hline Sedative as premedication & \\
\hline Midazolam & 28 \\
\hline Clonidin & 3 \\
\hline
\end{tabular}




\begin{tabular}{|l|l|}
\hline No & 0 \\
\hline No opioid intraoperative & \\
\hline Metamizole & 10 \\
\hline No & 21 \\
\hline Opioid intraoperative & \\
\hline Sufentanil & 31 \\
\hline Remifentanil & 4 \\
\hline Piritramide & 3 \\
\hline No & 0 \\
\hline Prednisolon & \\
\hline Yes & 31 \\
\hline No & 0 \\
\hline PONV prophylaxis & \\
\hline Yes & 4 \\
\hline No & 27 \\
\hline Clonidine perioperatively & \\
\hline Yes & 11 \\
\hline No & 21 \\
\hline Non-opioid intensive care unit & \\
\hline Metamizole & 27 \\
\hline Ibuprofen & 1 \\
\hline No & 4 \\
\hline Opioid in intensive care unit & \\
\hline Piritramide & 21 \\
\hline No & 10 \\
\hline Non-opioid on ward & \\
\hline Metamizole & 30 \\
\hline Ibuprofen & 1 \\
\hline No & 1 \\
\hline Opioid on ward & \\
\hline Fentanyl & 8 \\
\hline Tramadol & 11 \\
\hline No & 13 \\
\hline Physical pain therapy on ward & 29 \\
\hline Cold pack & 22 \\
\hline No & 3 \\
\hline Individual pain therapy instruction on ward available & \\
\hline Yes & 0 \\
\hline No & \\
\hline Pain documentation in patient chart & \\
\hline Yes & \\
\hline No & \\
\hline & \\
\hline & \\
\hline
\end{tabular}


Table 3 Relation between process and outcome parameters concerning postoperative pain after microvascular reconstruction with a radialis flap (part 1)

\begin{tabular}{|c|c|c|c|c|c|c|}
\hline & $\begin{array}{l}\text { Pain on } \\
\text { ambulation } \\
(0-10)\end{array}$ & $\begin{array}{l}\text { Maximum } \\
\text { pain intensity } \\
(0-10)\end{array}$ & $\begin{array}{l}\text { Minimum } \\
\text { pain intensity } \\
(0-10)\end{array}$ & $\begin{array}{l}\text { Satisfaction } \\
\text { with pain } \\
\text { intensity (0-15) }\end{array}$ & $\begin{array}{l}\text { Mobility } \\
\text { decreased } \\
(n)\end{array}$ & $\begin{array}{l}\text { Breathing } \\
\text { disturbance } \\
\text { (n) }\end{array}$ \\
\hline Age $($ median $=60.0$ years $)$ & 0.041 & 0.006 & 0.523 & 0.804 & 0.054 & 0.009 \\
\hline$\leq 60.0(n=15)$ & $5.9 \pm 2.7$ & $6.7 \pm 2.6$ & & & & $n=13$ \\
\hline$\geq 60.0(n=16)$ & $3.7 \pm 3.4$ & $1.6 \pm 1.5$ & & & & $n=6$ \\
\hline Gender & 0.543 & 0.992 & 0.92 & 0.349 & 0.247 & 1000 \\
\hline ASA (I + II vs. III) & 0.207 & 0.13 & 0.317 & 0.494 & 0.381 & 0.032 \\
\hline ASA I + II $(n=23)$ & & & & & & $n=17$ \\
\hline ASA III $(n=8)$ & & & & & & $n=2$ \\
\hline Duration of surgery (median $6.8 \mathrm{~h}$ ) & 0.815 & 0.435 & 0.578 & 0.832 & 1000 & 1000 \\
\hline \multicolumn{7}{|l|}{ Counselling } \\
\hline Specific vs. general vs. No & 0.008 & 0.009 & 0.147 & 0.004 & 0.632 & 0.432 \\
\hline Specific vs. general & 0.01 & 0.045 & & 0.014 & & \\
\hline Specific $(n=10)$ & $2.2 \pm 2.1$ & $3.0 \pm 2.6$ & & $13.7 \pm 3.1$ & & \\
\hline General $(n=15)$ & $5.6 \pm 3.1$ & $5.5 \pm 2.7$ & & $10.3 \pm 4.3$ & & \\
\hline Specific vs. No & 0.003 & 0.004 & & 0.001 & & \\
\hline Specific $(n=10)$ & $2.2 \pm 2.1$ & $3.0 \pm 2.6$ & & $13.7 \pm 3.1$ & & \\
\hline No $(n=6)$ & $6.8 \pm 2.8$ & $7.8 \pm 2.3$ & & $6.3 \pm 5.1$ & & \\
\hline General vs. No & 0.395 & 0.09 & & 0.088 & & \\
\hline Premedication midazolam & 0.812 & 0.908 & 0.169 & 0.614 & 0.634 & 0.363 \\
\hline Clonidine perioperative & 0.035 & 0.174 & 0.175 & 0.436 & 0.712 & 0.452 \\
\hline Yes $(n=11)$ & $6.5 \pm 2.9$ & & & & & \\
\hline No $(n=20)$ & $3.8 \pm 3.1$ & & & & & \\
\hline PONV prophylaxis & 0.241 & 0.394 & 0.241 & 0.135 & 0.577 & 1000 \\
\hline Non-opioid intraoperative & 0.789 & 0.842 & 0.367 & 0.322 & 0.685 & 0.447 \\
\hline Opioid in recovery room & 0.343 & 0.936 & 0.879 & 0.697 & 0.69 & 0.676 \\
\hline Non-opioid on ward & 0.452 & 0.452 & 0.613 & 0.871 & 1000 & 1000 \\
\hline
\end{tabular}


Table 4 Relation between process and outcome parameters concerning postoperative pain after microvascular reconstruction with a radialis flap (part 2)

\begin{tabular}{|c|c|c|c|c|c|c|c|}
\hline & $\begin{array}{l}\text { Sleeping } \\
\text { impairment } \\
(n)\end{array}$ & $\begin{array}{l}\text { Mood } \\
\text { disturbance } \\
(n)\end{array}$ & $\begin{array}{l}\text { Desire for } \\
\text { pain } \\
\text { medication } \\
(n)\end{array}$ & $\begin{array}{l}\text { Drowsiness } \\
(n)\end{array}$ & $\begin{array}{l}\text { Nausea } \\
(n)\end{array}$ & $\begin{array}{l}\text { Vomiting } \\
(n)\end{array}$ & $\begin{array}{l}\text { Chronic pain } \\
\text { preoperative } \\
(n)\end{array}$ \\
\hline Age $($ median $=60.0$ years $)$ & 0.113 & 0.006 & 0.166 & 0.722 & 1000 & 1000 & 0.685 \\
\hline$\leq 60.0(n=15)$ & & $n=12$ & & & & & \\
\hline$\geq 60.0(n=16)$ & & $n=7$ & & & & & \\
\hline Gender & 0.689 & 0.71 & 0.413 & 0.481 & 0.023 & 0.284 & 0.481 \\
\hline Male $(n=18)$ & & & & & $n=0$ & & \\
\hline Female $(n=13)$ & & & & & $n=4$ & & \\
\hline ASA (I + II vs. III) & 0.403 & 0.676 & 0.335 & 0.24 & 1000 & 1000 & 1000 \\
\hline $\begin{array}{l}\text { Duration of surgery (median } \\
6.8 \mathrm{~h} \text { ) }\end{array}$ & 1000 & 0.274 & 1000 & 1000 & 0.641 & 0.641 & 0.108 \\
\hline $\begin{array}{l}\text { Counselling } \\
\text { specific vs. general vs. no }\end{array}$ & 0.218 & 0.681 & 0.009 & 0.511 & 0.255 & 0.255 & 0.281 \\
\hline Specific vs. general & & & 0.14 & & & & \\
\hline Specific vs. no & & & 0.004 & & & & \\
\hline Specific $(n=0)$ & & & $n=0$ & & & & \\
\hline No $(n=6)$ & & & $n=4$ & & & & \\
\hline General vs. no & & & 0.046 & & & & \\
\hline General $(n=15)$ & & & $n=3$ & & & & \\
\hline No $(n=6)$ & & & $n=4$ & & & & \\
\hline Premedication midazolam & 0.633 & 1000 & 1000 & 0.021 & 0.561 & 1000 & 0.663 \\
\hline Given $(n=6)$ & & & & $n=6$ & & & \\
\hline Not given $(n=25)$ & & & & $n=11$ & & & \\
\hline
\end{tabular}




\begin{tabular}{|l|l|l|l|l|l|l|l|}
\hline Clonidine perioperative & 0.676 & 1000 & 1000 & 0.477 & 0.269 & 0.269 & 1000 \\
\hline PONV prophylaxis & 0.325 & 0.641 & 0.55 & 0.657 & 0.628 & 0.628 & 0.55 \\
\hline Non-opioid intraoperative & 0.222 & 0.127 & 0.379 & 0.441 & 1000 & 1000 \\
\hline Opioid in recovery room & 1000 & 1000 & 1000 & 0.24 & 1000 & 1000 & 0.69 \\
\hline Non-opioid on ward & 1000 & 1000 & 1000 & 1000 & 1000 & 1000 & 1000 \\
\hline Opioid on ward & 0.228 & 0.484 & 0.099 & 0.157 & 0.023 & 0.284 & 0.01 \\
\hline$\quad$ Yes (n= 18) & & & & & $n=4$ & & $n=8$ \\
\hline No (n= 13) & & & & $n=0$ & & $n=0$ \\
\hline
\end{tabular}


All calculations were conducted with SPSS V 21.0 for Windows (SPSS, Inc., Chicago, IL).

\section{Results}

A total of 31 patients was enrolled. Eighteen (58.1\%) patients were male and 13 (41.9\%) female. Mean age was $59.97 \pm 15.04$ years at the time of evaluation. Six (19.4 \%) patients regularly used pain medicaments for pre-existing chronic pain related to other diseases. One (3.2\%) patient was classified under ASA 1, 22 (71.0\%) under ASA 2, and 8 (25.8\%) under ASA 3. Mean duration of surgery was $6.80 \pm 2.17 \mathrm{~h}$. Twenty-five $(80.7 \%)$ patients received ablative tumour surgery and primary reconstruction due to a carcinoma. Twenty-three $(92.0 \%)$ of these patients received a neck dissection. In six (19.4\%) patients, surgery was performed as a secondary reconstructive procedure due to other reasons.

Results of the QUIPS questionnaire regarding the outcome of the performed postoperative pain management and pain-related parameters on the first postoperative day are given in Table 1. NRS mean of minimum pain was $1.7 \pm 2$.2. Pain under strain was increased to $4.7 \pm 3.2$. Maximum pain levels showed a mean of $5.1 \pm 3.1$. Nineteen (61.3\%) patients presented pain levels $\geq 4$. Overall satisfaction with pain therapy was moderate $(10.6 \pm 4.8)$.

Most patients reported to have received preoperative pain counselling ( $n=25,80.6 \%$ ). In 15 (48.4 \%) patients, counselling was specific and in 10 (32.3\%) it was general.

Concerning pain-related complaints, nearly two thirds of the patients reported pain-related impairment of mobility, breathing and mood. Nearly half of the patients reported drowsiness. Nearly one quarters reported pain-related sleeping impairment. Nearly every tenth patient reported postoperative nausea and vomiting. Seven $(22.6 \%)$ of the patients desired additional pain medication at the time of evaluation.

Results of the selected process parameters of the performed pain management are given in Table 2. Standard sedative for premedication was in $90.3 \%$ midazolam. Intraoperatively, all patients received sufentanil, some additionally remifentanil or piritramid. Metamizol as a non-opioid was intraoperatively applied in 10 (32.3\%) patients. Clonidine was perioperatively applied in 11 (35.5\%) patients. Prophylaxis of postoperative nausea and vomitus (PONV) was performed in only 4 (12.9\%) patients by granisetron and/or dexamethasone.

In the intensive care unit, 28 (90.3\%) patients received medication with a non-opioid, nearly always metamizol. Twenty-one (67.7\%) patients received additionally piritramid as opioid.

On ward, all patients received a non-opioid medication. The predominant non-opioid was metamizol $(n=30,96.8 \%)$ applied in a dosage of $4 \times 1 \mathrm{~g}$. Eleven patients $(35.5 \%)$ received tramadol and eight $(25.8 \%)$ patients a fentanyl skin patch as opioid. Thirteen (41.9\%) patients did not receive opioid medication. For all individuals, patients' charts included instructions for pain therapy. Documentation of patients' pain was recorded in 29 (93.5\%) of the charts.

Relations between the above described outcome and process parameters are given in Tables 3 and 4 . Patients exhibiting an age below the median of 60.0 years presented significant higher levels of pain under strain $(p=.041)$ and maximum pain $(p=.006)$ as well as a significant higher rate of breathing 
disturbance $(p=.009)$ and mood disturbance $(p=.006)$. Patients with an ASA I or II reported significant higher rates of breathing disturbance $(p=.032)$ compared to patients exhibiting an ASA III. Females presented significant higher rates of postoperative nausea compared to males $(p=.023)$. In the group receiving perioperative clonidine, significant higher pain on ambulation intensity levels was observed $(p=.035)$. Patients receiving an opioid on ward presented in significant higher rates postoperative nausea $(p=.023$ ) compared to those receiving a non-opioid medication only. Patients exhibiting chronic pain received significant more often opioids than other patients $(p=.01)$.

Pain counselling showed a significant impact on pain under strain $(p=.008)$, maximum pain intensity $(p=.004)$, satisfaction with pain intensity levels $(p=.001)$ and the desire of additional pain medication $(p=.009)$. When comparing those groups receiving a specific, general or no pain management counselling, best results were always obtained, when a specific preoperative pain counselling had been performed (see Tables 3 and 4). Whether primary or secondary reconstruction was performed did not influence the investigated parameters. Whether a neck dissection or no neck dissection was performed did not show significant influence as well.

\section{Discussion}

\section{Discussion of the method}

Adequate pain management is an essential part of postoperative care. Inadequate postoperative pain intensities result in patient discomfort and may decrease patient satisfaction [15]. It seems also to increase the risk for pulmonary and cardiovascular complications and to contribute to the risk of development of chronic pain [16-19].

Despite these relations, why is inadequate pain management widespread? Inadequate knowledge among health care professionals, patients, lack of institutional commitment, regulatory concerns and limited access to and reimbursement for interdisciplinary care pose significant barriers to effective pain management $[20,2]$.

To optimize their pain management, clinicians normally seek advice on principles for postoperative pain management in general guidelines for or in major textbooks [2]. Unfortunately, the data used to construct the tables provided by these guidelines and books are primarily originating from studies in dental procedures or other relatively poorly defined surgical procedures [2].

To improve the described insufficient quality of postoperative pain management in daily routine and beyond guidelines, it has been recommended to implement a continuously on-going monitoring system of the quality of postoperative pain management [21]. Such a monitoring system should include structure and outcome parameters and should be procedure specific [20, 22].

The procedure-specific evaluation is of special importance in this context as it is current consensus that different surgical procedures lead to specific pain types and high varying amount of pain. Furthermore, it has been demonstrated that the analgetic efficacy of different analgetics depends on the performed surgery [23].

At this background, the Germany-wide outcome-oriented project called Quality Improvement in Postoperative Pain Management (QUIPS) was developed in 2005. It consists of a standardized data 
acquisition and analysis of process and quality indicators [13]. The QUIPS questionnaire was developed on the basis of the Brief Pain Inventory (BPI) and recommendations of the American Pain Society (APS) [20]. The QUIPS project is open to every German hospital and web based (http://www.Quipsprojekt.de).

After assessment of patients' process and outcome parameters, standardized data sets are made anonymous and transferred to the external QUIPS database. This database allows the participating hospitals a procedure-specific internal benchmarking and on-going monitoring of processes of postoperative pain management results. Also an anonymous procedure-specific comparison of postoperative pain management outcome of the different participating hospitals in terms of an external benchmarking is possible. Such a standardized benchmarking system supports significant improvement of postoperative pain management [24].

Data of the presented study was raised by using the QUIPS questionnaire, but was not transferred to the benchmark server of QUIPS. QUIPS has been established to improve the quality of postoperative pain management on ward in patients directly transferred via recovery room to ward. In the presented investigation, patients had to be transferred to our intensive care unit prior to be back on ward. Thus, we could not perform an external benchmark. However, data should be able to give an adequate feedback about the current situation of postoperative pain management on our ward.

To adequately rate results, it has to be mentioned that the presented results do not allow conclusions about the further course of postoperative pain after the investigated first postoperative day. Normally, pain decreases after the first postoperative day. It may be assumed that the performed postoperative pain therapy is effective over the first postoperative day on [16].

Another limitation is the absence of preoperative pain assessment. Thus, we could not distinguish between pain caused by functional disorders, especially in patients that had earlier surgery and underwent secondary carcinoma surgery or secondary reconstruction, and surgically induced pain. Due to the study design of QUIPS, preoperative data of preexisting pain levels were not raised. It was only investigated whether there was preoperative pain medication. However, this seems not to be from a decisive impact on the results, as preoperative pain medication showed no significant correlation to the investigated parameters. In the corresponding pain therapy of these patients, we observed a significant higher rate of opioid use $(p=.01)$.

Also a Hawthorne effect cannot be excluded. Furthermore, data have a monocentric character. Thus, it is not possible to conclude from our data to a general situation.

Discussion of the results

Whether primary or secondary reconstruction was performed did not influence the investigated parameters. We think that this is an indication that postoperative pain levels after microvascular reconstruction with a radialis flap are widely associated with the amount and performance of reconstruction. This assumption may be underlined by the fact that we could not find a relation between the performance of lymph node surgery or not and postoperative pain intensity levels. 
NRS means of pain ranged from 1.7 to 5.1. Mean of maximum pain was 5.1 and was comparable to earlier observed maximum pain levels in patients undergoing surgical procedures, e.g. a laparoscopic appendectomy (5.2) [13].

Overall 19 (61.3 \%) patients showed pain intensity levels $\geq 4$. NRS intensity levels $\geq 4$ are associated with increasing discomfort and functional constriction due to pain. [25] This leads to the conclusion that $61 \%$ of our patients exhibited inadequate pain management. The overall mediocre satisfaction with pain therapy seems to underline this appraisal (10.6). Most earlier studies evaluating surgeon-guided postoperative pain management, including an earlier study of our group evaluating midfacial fracture repair and published in this journal [26], show similar amount of inadequate pain management, which underlines the need of further activity in this field.

The basic analgetic medication on ward consisted of non-opioids, which received all patients. Nonopioids are currently considered to be an effective standard medication with oral and fast application after surgery to reduce postoperative pain [27]. Thus, all patients received a non-opioid medication with metamizol or ibuprofen. Despite this $100 \%$ non-opioid medication, only $58.1 \%$ of our patients received a medication with an opioid. It seems that the above described inadequate pain management in $61 \%$ of our patients was primarily linked to opioid undersupply which is a worldwide phenomenon [4-6]. Although opioids are associated with problems like opioid-induced constipation or nausea, as we observed in our patients, they have significant therapeutic value in the treatment of severe pain [28]. Each pain management concept should include defined steps of escalation in case of insufficiently controlled pain, e.g. by additional and early application of opioids on an as-needed base. The significant higher rate of patients with pre-existing chronic pain receiving opioids confirms the significance of opioids to reduce severe pain $(p=.01)$.

Regarding the investigated relations between process and outcome parameters, we found significant higher levels of pain under strain and maximum pain as well as significant higher rates of breathing and mood disturbance in patients exhibiting age below the median of 60 years. Similar results have been reported in earlier studies. It seems that older patients are more willing to accept and tolerate postoperative pain. It has also been reported that they tend to less frequently inform staff of their pain, because they do not want to disturb [29,30]. The observed higher rates of reported breathing disturbance in patients exhibiting an ASA I or II compared to patients with an ASA III maybe underline this appraisal, as patients exhibiting an ASA I or II are normally younger than those exhibiting an ASA III.

Preoperative pain counselling showed bigger influence on postoperative pain intensity levels in all investigated pain entities (see Tables 3 and 4). Patients receiving specific preoperative pain counselling experience significant lower pain levels than patients receiving general or no counselling. It seems that preoperative counselling reduces stress and fear and help to reduce wrong expectations [31-33]. This result underlines the essential importance of preoperative pain counselling, which should be specific to be its best.

Furthermore, we observed significant more postoperative nausea in females than in males. This result seems not to be gender but medication linked, as the four patients exhibiting nausea received all opioids. 
To avoid such unfortunate results, the existing, mostly on a local basis established different postoperative pain management concepts in patients undergoing cranio-maxillofacial surgery, should be standardized. This is desirable especially in patients undergoing oncologic surgery, to whom opioids should be provided on a regular basis in their postoperative pain management [34]. QUIPS can help us to learn to estimate the significance of such standardization and its potential impact on patients' wellbeing.

\section{Conclusion}

QUIPS is an easy and effective tool to measure postoperative pain and rate the quality of postoperative pain management. Of our patients, $61 \%$ showed insufficient postoperative pain management. Especially an undersupply with opioids was responsible for this result. The observed significant lower pain intensity levels in patients having received preoperative counselling underline the estimation of preoperative pain counselling, which should be specific to get the best results.

\section{References}

Kehlet $\mathrm{H}$ (2004) Effect of postoperative pain treatment on outcome-current status and future strategies. Langenbeck's Arch Surg 389:244-249. doi:10.1007/s00423-004-0460-4

Kehlet H, Wilkinson RC, Fischer HB, Camu F (2007) PROSPECT: evidence-based, procedure-specific postoperative pain management. Best Pract Res Clin Anaesthesiol 21:149-159

Gartner R, Jensen MB, Nielsen J, Ewertz M, Kroman N, Kehlet H (2009) Prevalence of and factors associated with persistent pain following breast cancer surgery. JAMA 302:1985-1992. doi:10.1001/jama.2009.1568

Rathmell JP, Wu CL, Sinatra RS, Ballantyne JC, Ginsberg B, Gordon DB, Liu SS, Perkins FM, Reuben SS, Rosenquist RW, Viscusi ER (2006) Acute post-surgical pain management: a critical appraisal of current practice, December 2-4, 2005. Reg Anesth Pain Med 31:1-42. doi:10.1016/j.rapm.2006.05.002

Apfelbaum JL, Chen C, Mehta SS, Gan TJ (2003) Postoperative pain experience: results from a national survey suggest postoperative pain continues to be undermanaged. Anesth Analg 97:534-540 table of contents

Benhamou D, Berti M, Brodner G, De Andres J, Draisci G, Moreno-Azcoita M, Neugebauer EA, Schwenk W, Torres LM, Viel E (2008) Postoperative Analgesic Therapy Observational Survey (PATHOS): a practice pattern study in 7 central/southern European countries. Pain 136:134-141. doi:10.1016/j.pain.2007.06.028

Fries BE, Simon SE, Morris JN, Flodstrom C, Bookstein FL (2001) Pain in U.S. nursing homes: validating a pain scale for the minimum data set. Gerontologist 41:173-179

Gureje O, Simon GE, Von Korff M (2001) A cross-national study of the course of persistent pain in primary care. Pain 92:195-200

Warfield CA, Kahn CH (1995) Acute pain management. Programs in U.S. hospitals and experiences and attitudes among U.S. adults. Anesthesiology 83:1090-1094

Fletcher D, Fermanian C, Mardaye A, Aegerter P (2008) A patient-based national survey on postoperative pain management in France reveals significant achievements and persistent challenges. Pain 137:441-451. doi:10.1016/j.pain.2008.02.026

Mularski RA, White-Chu F, Overbay D, Miller L, Asch SM, Ganzini L (2006) Measuring pain as the 5th vital sign does not improve quality of pain management. J Gen Intern Med 21:607-612. doi:10.1111/j.1525-1497.2006.00415.x 
Gordon DB, Dahl JL (2004) Quality improvement challenges in pain management. Pain 107:1-4

Meissner W, Mescha S, Rothaug J, Zwacka S, Goettermann A, Ulrich K, Schleppers A (2008) Quality improvement in postoperative pain management: results from the QUIPS project. Dtsch Arztebl Int 105:865-870. doi:10.3238/arztebl.2008.0865

Wolff K-D, Hölzle F (2011) Raising of microvascular flaps-a systematic approach. Springer-Verlag, Berlin Heidelberg

Myles PS, Williams DL, Hendrata M, Anderson H, Weeks AM (2000) Patient satisfaction after anaesthesia and surgery: results of a prospective survey of 10,811 patients. Br J Anaesth 84 :610

Sommer M, Geurts JW, Stessel B, Kessels AG, Peters ML, Patijn J, van Kleef M, Kremer B, Marcus MA (2009) Prevalence and predictors of postoperative pain after ear, nose, and throat surgery. Arch Otolaryngol Head Neck Surg 135:124-130. doi:10.1001/archoto.2009.3

Ballantyne JC, Carr DB, deFerranti S, Suarez T, Lau J, Chalmers TC, Angelillo IF, Mosteller F (1998) The comparative effects of postoperative analgesic therapies on pulmonary outcome: cumulative meta-analyses of randomized, controlled trials. Anesth Analg 86:598-612

Beattie WS, Buckley DN, Forrest JB (1993) Epidural morphine reduces the risk of postoperative myocardial ischaemia in patients with cardiac risk factors. Can J Anaesth 40:532-541. doi:10.1007/BF03009738

Neugebauer E, Sauerland S, Keck V, Simanski C, Witte J (2003) Surgical pain management. A Germanywide survey including the effect of clinical guidelines. Chirurg 74:235-238. doi:10.1007/s00104003-0615-9

Gordon DB, Dahl JL, Miaskowski C, McCarberg B, Todd KH, Paice JA, Lipman AG, Bookbinder M, Sanders SH, Turk DC, Carr DB (2005) American Pain Society recommendations for improving the quality of acute and cancer pain management: American Pain Society Quality of Care Task Force. Arch Intern Med 165:1574-1580. doi:10.1001/archinte.165.14.1574

Meissner W, Ullrich K, Zwacka S (2006) Benchmarking as a tool of continuous quality improvement in postoperative pain management. Eur J Anaesthesiol 23:142-148. doi:10.1017/S026502150500205X

Meissner W (2010) Focus on pain. quality assurance in pain treatment. Anasthesiol Intensivmed Notfallmed Schmerzther 45:718-719. doi:10.1055/s-0030-1268874

Hyllested M, Jones S, Pedersen JL, Kehlet H (2002) Comparative effect of paracetamol, NSAIDs or their combination in postoperative pain management: a qualitative review. Br J Anaesth 88:199-214

Lehmkuhl D, Meissner W, Neugebauer EA (2011) Evaluation of the "initiative pain-free clinic" for quality improvement in postoperative pain management. A prospective controlled study. Schmerz 25:508-515. doi:10.1007/s00482-011-1054-z

Laubenthal H, Deutsche Interdisziplinäre Vereinigung für Schmerztherapie (2008) S3-Leitlinie Behandlung akuter perioperativer und posttraumatischer Schmerzen mit 97 Tabellen. Dt. ÄrzteVerl, Köln

Raschke GF, Peisker A, Rieger U, Djedovic G, Guentsch A, Schaefer O, Venth E, Dammeier MG, Meissner W (2015) Quality of postoperative pain management after midfacial fracture repair-an outcome-oriented study. Clin Oral Investig 19:619-625. doi:10.1007/s00784-014-1283-5

Savoia G, Alampi D, Amantea B, Ambrosio F, Arcioni R, Berti M, Bettelli G, Bertini L, Bosco M, Casati A, Castelletti I, Carassiti M, Coluzzi F, Costantini A, Danelli G, Evangelista M, Finco G, Gatti A, Gravino E, Launo C, Loreto M, Mediati R, Mokini Z, Mondello E, Palermo S, Paoletti F, Paolicchi A, Petrini F, Piacevoli Q, Rizza A, Sabato AF, Santangelo E, Troglio E, Mattia C (2010) 
Postoperative pain treatment SIAARTI Recommendations 2010. Short version. Minerva Anestesiol 76:657-667

Meissner W, Leyendecker P, Mueller-Lissner S, Nadstawek J, Hopp M, Ruckes C, Wirz S, Fleischer W, Reimer K (2009) A randomised controlled trial with prolonged-release oral oxycodone and naloxone to prevent and reverse opioid-induced constipation. Eur J Pain 13:56-64. doi:10.1016/j.ejpain.2008.06.012

Bisgaard T, Klarskov B, Rosenberg J, Kehlet H (2001) Characteristics and prediction of early pain after laparoscopic cholecystectomy. Pain 90:261-269

Catananti C, Gambassi G (2010) Pain assessment in the elderly. Surg Oncol 19:140-148. doi:10.1016/j.suronc.2009.11.010

Sjoling M, Nordahl G, Olofsson N, Asplund K (2003) The impact of preoperative information on state anxiety, postoperative pain and satisfaction with pain management. Patient Educ Couns 51:169-176

Doering S, Katzlberger F, Rumpold G, Roessler S, Hofstoetter B, Schatz DS, Behensky H, Krismer M, Luz G, Innerhofer P, Benzer H, Saria A, Schuessler G (2000) Videotape preparation of patients before hip replacement surgery reduces stress. Psychosom Med 62:365-373

Ettrich U, Seifert J, Scharnagel R, Gunther KP (2007) A multimodal and multidisciplinary postoperative pain management concept. Der Orthopade 36(544):546-551. doi:10.1007/s00132-007-1103-6

Blanchard D, Bollet M, Dreyer C, Binczak M, Calmels P, Couturaud C, Espitalier F, Navez M, Perrichon C, Testelin S, Albert S, Morinière S, SFORL Work Group (2014) Management of somatic pain induced by head and neck cancer treatment: pain following radiation therapy and chemotherapy. Guidelines of the French Otorhinolaryngology Head and Neck Surgery Society (SFORL). Eur Ann Otorhinolaryngol Head Neck Dis 131:253-256.

doi:10.1016/j.anorl.2014.07.001 